Supporting Information

\title{
Synthesis, Physicochemical and Biochemical Studies of 1',2'-Oxetane Constrained Adenosine and Guanosine Modified Oligonucleotides, and their Comparison with those of the Corresponding Cytidine and Thymidine Analogs
}

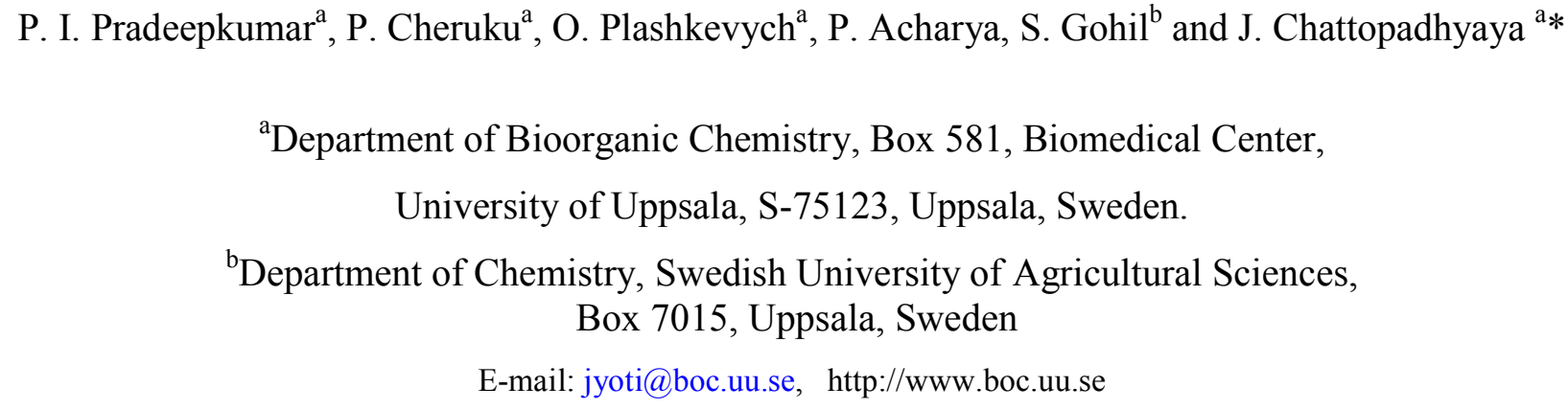

\section{Table of Contents}

$\begin{array}{lr}\text { (1) General Experimental Procedures } & \mathrm{S} 3\end{array}$

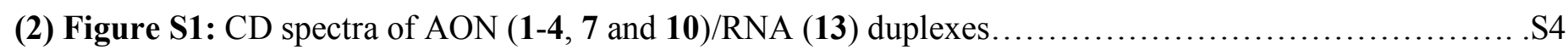

(3) Figure S2: PAGE analysis of the DNase 1 degradation of AONs (1)- (4), (7) and (11). S5

(4) Figure S3: PAGE analysis of the snake venom phosphodiesterase (SVPDE) degradation of AONs (1), (7), (12), (8), (9) and (11).

(5) Figure S4: PAGE analysis of the degradation of AONs (1), (7), (12), (8), (9) and (11) in human serum. S7 
(6) Table S1: Experimental and calculated vicinal ${ }^{3} J_{\mathrm{H}, \mathrm{H}}$ coupling constants

(7) Table S2: Carbon chemical shifts in ppm ( $\delta$ scale) of the oxetane nucleosides 1a $(\underline{\mathbf{C}}), \mathbf{1 b}(\underline{\mathbf{T}})$, $\mathbf{1 c}(\underline{\mathbf{A}})$ and $\mathbf{1 d}(\underline{\mathbf{G}})$.

(8) Figures S5-S16: ${ }^{13} \mathrm{C}-\mathrm{NMR}$ spectra of compounds $\mathbf{1 5 - 2 2}$

(9) Figures S17 \& S18: ${ }^{31}$ P-NMR spectra of compounds 23a and 23b

(10) Figure S19: ${ }^{13} \mathrm{C}-\mathrm{NMR}$ spectrum of $9-\left(1^{\prime}, 3\right.$ '- $O$-anhydro- $\beta$ - $\underline{D}-$ psicofuranosyl)adenine (1c)

(11) Figure S20: ${ }^{13} \mathrm{C}-\mathrm{NMR}$ spectrum of $9-\left(1^{\prime}, 3^{\prime}-O\right.$-anhydro- $\beta$ - $\left.\underline{\mathrm{D}}-\mathrm{psicofuranosyl}\right)$ guanine (1d) 


\section{General experimental procedures}

All solvents were dried according to the reported procedures ${ }^{1}$. The chromatographic separations were performed on G60 silica gel. Thin layer chromatography (TLC) was performed on pre-coated silica gel $60 \mathrm{~F}_{254}$ glass backed plates. ${ }^{1} \mathrm{H}-\mathrm{NMR}$ spectra were recorded at 270 or $600 \mathrm{MHz}$ using TMS (0.0 ppm) and DMSO- $d_{6}(2.6 \mathrm{ppm})$ peaks as internal standards. ${ }^{13} \mathrm{C}-\mathrm{NMR}$ spectra were recorded with at $67.9 \mathrm{MHz}$ using the central peak of $\mathrm{CDCl}_{3}(76.9 \mathrm{ppm})$ or DMSO- $d_{6}(39.6 \mathrm{ppm})$ as internal standard. ${ }^{31} \mathrm{P}-\mathrm{NMR}$ spectra were recorded at $109.4 \mathrm{MHz}$ using $85 \%$ phosphoric acid as an external standard. Chemical shifts are reported in ppm ( $\delta$ scale). Signal assignments for each compound were achieved by 2D-NMR experiments $\left({ }^{1} \mathrm{H}-{ }^{1} \mathrm{H}\right.$ COSY, ${ }^{1} \mathrm{H}_{-}{ }^{13} \mathrm{C}$ HETCOR, COLOC) using standard software. Thermal denaturation experiments were performed on a PC-computer interfaced UV/VIS spectrophotometer with Peltier temperature controller. MALDI spectra were recorded in negative mode and FAB-HRMS on positive mode.

1) Perrin, D.D.; Armarego, W. L. F.; Perrin, D. R. Purification of Laboratory Chemicals. 1985, Pergamon Press, Oxford. 


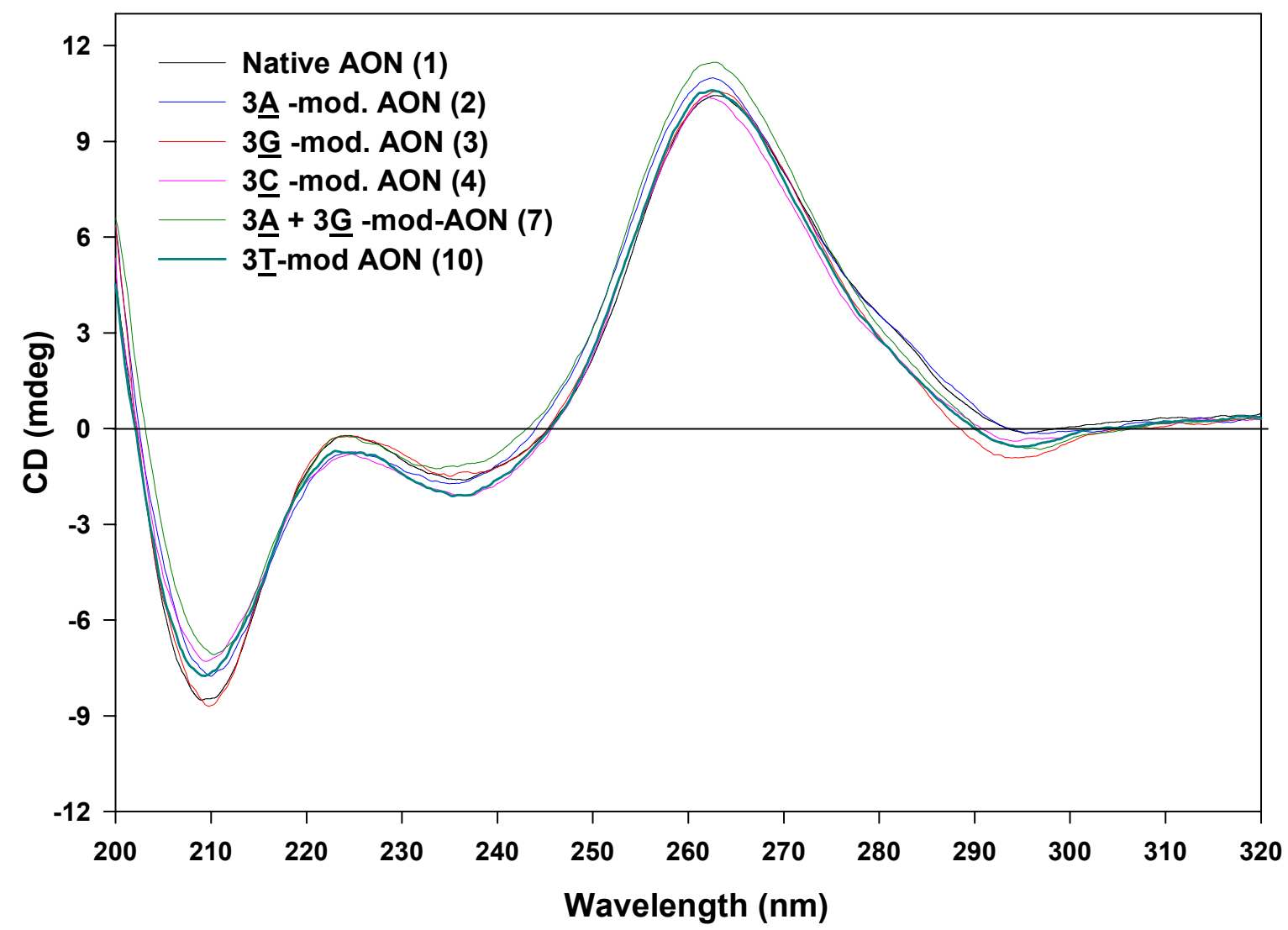

Figure S1. CD spectra of AON (1-4, 7 and 10)/RNA (13) duplexes at 293K. The total strand $(\mathrm{AON}+\mathrm{RNA})$ concentration was $10 \mu \mathrm{M}$. 


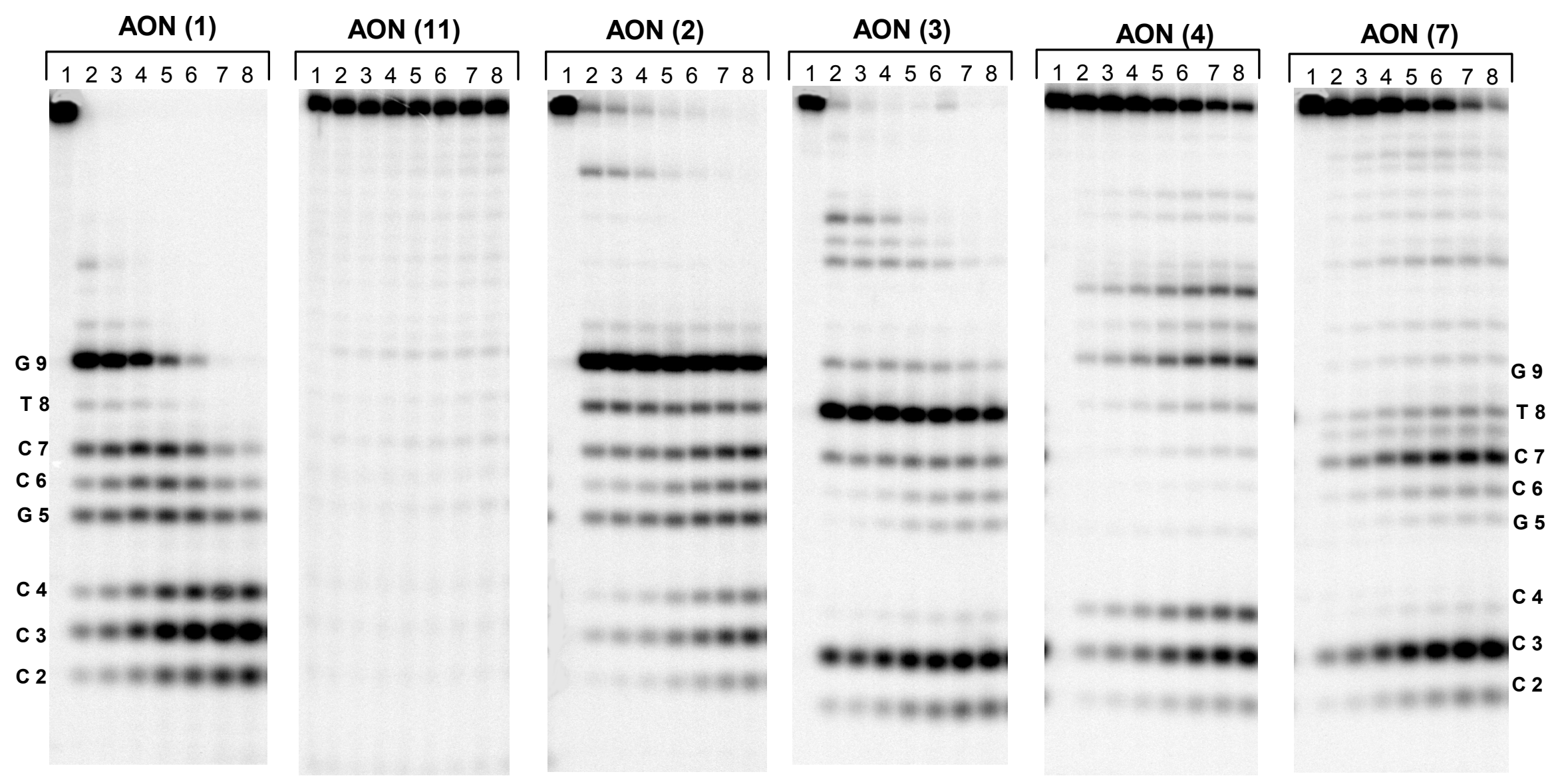

Figure S2. PAGE analysis of the DNase 1 degradation of AON (1)- (4), (7) and (11). Lanes 1 to 8 represent the time points after 0,15 , and $30 \mathrm{~min}, 1,2,4,8,12 \mathrm{~h}$ of reaction. The $\%$ of AON left after $4 \mathrm{~h}$ of incubation: $0 \%$ of AON (1), $91 \%$ of $\mathrm{AON}(11), 0 \%$ of $\mathrm{AON}(2), 0 \%$ of $\mathrm{AON}(3), 50 \%$ of $\mathrm{AON}(4)$ and $30 \%$ of $\mathrm{AON}(7)$. 


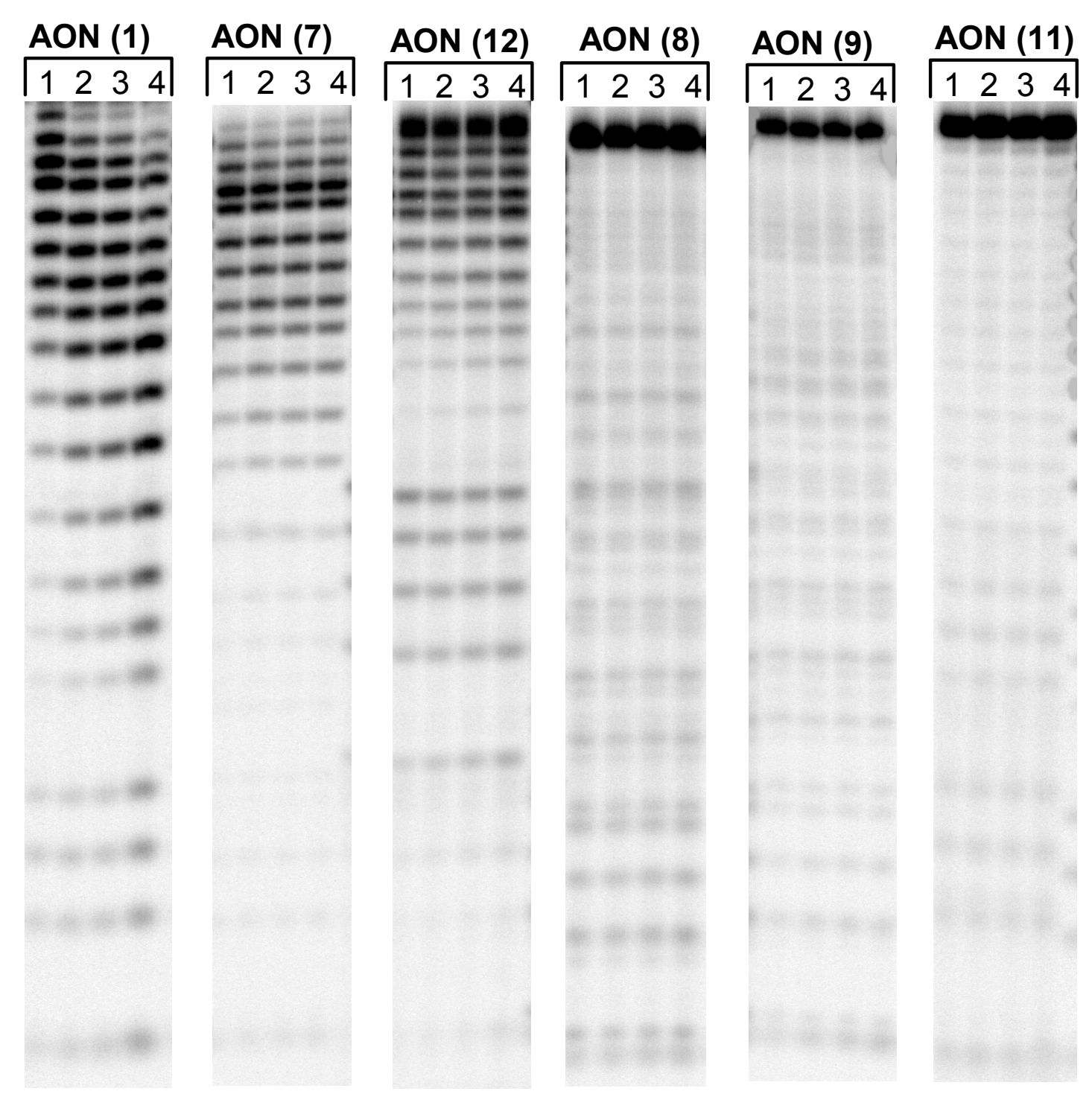

Figure S3. PAGE analysis of the snake venom phosphodiesterase (SVPDE) degradation of AONs (1), (7), (12), (8), (9) and (11). Lanes 1 to 4 represents the time points after 1, 2, 4 and $24 \mathrm{~h}$ of reaction. The $\%$ of AON left after $24 \mathrm{~h}$ of incubation with enzyme: $0 \%$ of AON (1), $0 \%$ of AON (7), 36\% of AON (12), $92 \%$ of AON (8), $93 \%$ of AON (9) and $96 \%$ of AON (11). 
AON (1)

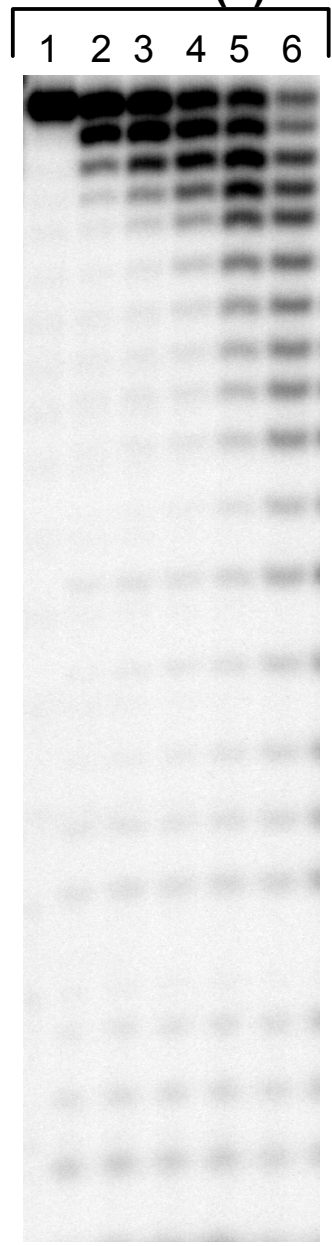

AON (7)

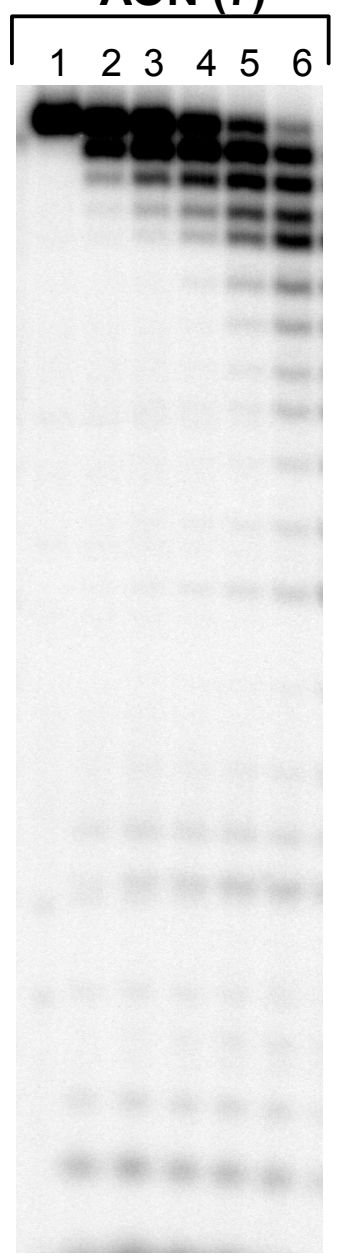

AON (12)

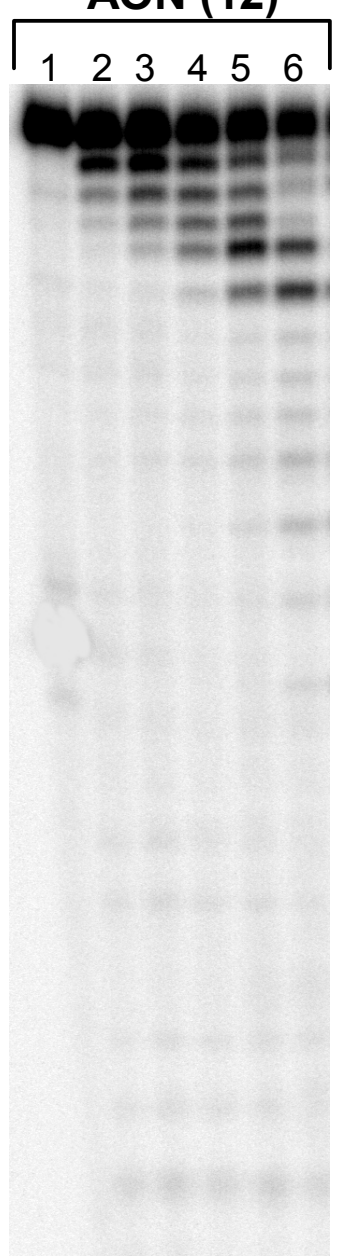

AON (8)

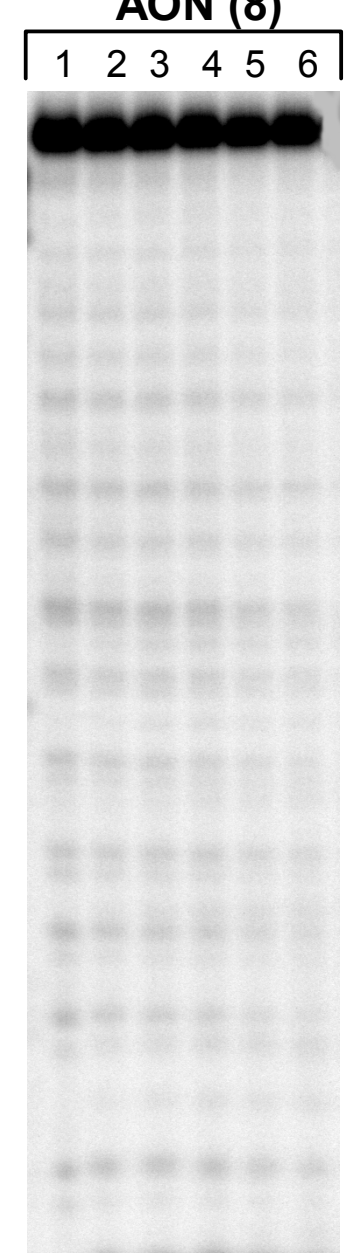

AON (9)
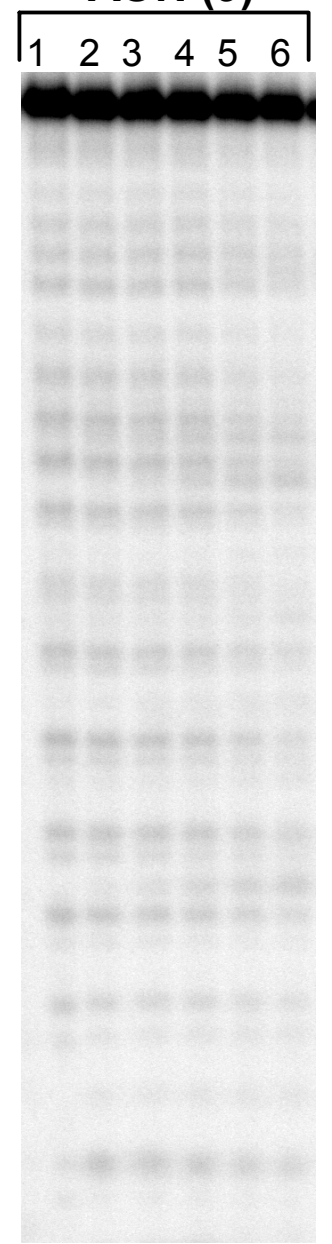

AON (11)

$\begin{array}{llllll}1 & 2 & 3 & 4 & 5 & 6\end{array}$

Figure S4. PAGE analysis of the degradation of AONs (1), (7), (12), (8), (9) and (11) in human serum. Lanes 1 to 6 represents the time points after 0,15 and $30 \mathrm{~min}, 1,2$ and $9 \mathrm{~h}$ of reaction. The $\%$ of AON left after $12 \mathrm{~h}$ of incubation: $0 \%$ of AON (1), $0 \%$ of AON (7), $48 \%$ of AON (12), 90\% of AON (8), 87\% of AON (9), and $78 \%$ of AON (11). 
Table S1. Experimental and calculated vicinal ${ }^{3} J_{\mathrm{H}, \mathrm{H}}$ coupling constants for the H-3',H-4' and H-4',H-5' vicinal proton-proton interaction in the oxetane-modified nucleosides. Theoretical couplings are calculated using generalized Karplus equation ${ }^{36}$ and the $\mathrm{H}^{\prime}-\mathrm{C} 3{ }^{\prime}-\mathrm{C} 4 '-\mathrm{H} 4$ ' and $\mathrm{H} 4{ }^{\prime}-\mathrm{C} 4{ }^{\prime}-\mathrm{C} 5 '-\mathrm{H} 5$ ' torsion angles are from the $a b$ initio geometry optimized structures.

\begin{tabular}{|c|c|c|c|c|c|c|}
\hline Nucleoside & Protons & $\begin{array}{l}\text { Torsion } \\
\phi_{\mathrm{H}, \mathrm{H}}^{\mathrm{a}, \mathrm{b}},\left(^{\mathrm{o}}\right)\end{array}$ & $\begin{array}{l}{ }^{3} J_{\mathrm{H}, \mathrm{H}} \exp . \\
(\mathrm{Hz})\end{array}$ & $\begin{array}{l}{ }^{3} J_{\mathrm{H}, \mathrm{H}} \text { calc. }{ }^{\mathrm{c}}, \\
(\mathrm{Hz})\end{array}$ & $\begin{array}{l}{ }^{3} J_{\mathrm{H}, \mathrm{H}}, \\
(\mathrm{Hz})\end{array}$ & $\begin{array}{l}\text { RMSd, } \\
(\mathrm{Hz})\end{array}$ \\
\hline \multirow{2}{*}{ Oxetane-T (1b) } & H-3',H-4' & 43.27 & 3.90 & 3.86 & 0.04 & 0.03 \\
\hline & H-4',H-5' & -163.13 & 8.55 & 8.00 & 0.55 & 0.39 \\
\hline \multirow{2}{*}{ Oxetane- $\underline{C}(1 b)$} & H-3',H-4' & 43.75 & 3.90 & 3.81 & 0.09 & 0.06 \\
\hline & H-4',H-5' & -164.06 & 8.55 & 7.99 & 0.56 & 0.40 \\
\hline \multirow{2}{*}{ Oxetane- $\underline{\mathbf{A}}$ (1c) } & H-3',H-4' & 43.30 & 3.73 & 3.86 & -0.13 & 0.09 \\
\hline & H-4',H-5' & -163.04 & 8.55 & 7.92 & 0.63 & 0.45 \\
\hline \multirow{2}{*}{ Oxetane-G (1d) } & H-3',H-4' & 43.80 & 3.73 & 3.81 & -0.08 & 0.06 \\
\hline & H-4',H-5' & -163.78 & 8.62 & 7.97 & 0.65 & 0.46 \\
\hline
\end{tabular}

${ }^{a}$ From ab initio 6-31G* Hartree-Fock geometry optimized using the Gaussian 98 program. ${ }^{45}$

${ }^{b} \mathrm{H} 3$ '-C3'-C4'-H4' and H4'-C4'-C5'-H5' torsions for the H3'-H4' and H4'-H5' vicinal proton-proton interactions, respectively.

${ }^{\mathrm{c}}$ Calculated using generalized Karplus equation by Altona et. al. ${ }^{36}$ 
Table S2: Carbon chemical shifts in ppm ( $\Delta$ scale) of the oxetane nucleosides $1 \mathbf{a}^{*}(\underline{\mathbf{C}}), \mathbf{1 b}^{*}(\underline{\mathbf{T}}), \mathbf{1 c}(\underline{\mathbf{A}})$ and $\mathbf{1 d}$ $(\underline{\mathbf{G}})$. The ${ }^{13} \mathrm{C}-\mathrm{NMR}$ spectra were recorded in DMSO- $d_{6}$ with methanol- $d_{4}$ at $67.9 \mathrm{MHz}$ using the central peak of DMSO- $d_{6}(39.6 \mathrm{ppm})$ as internal standard.

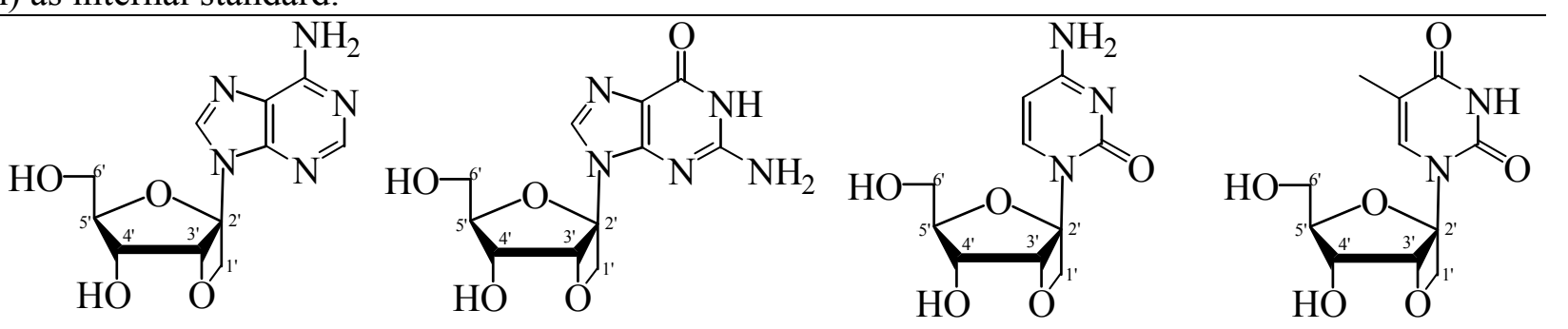

\begin{tabular}{|c|c|c|c|c|}
\hline C-1' & 78.6 & 78.6 & 78.6 & 78.2 \\
\hline C-2' & 88.4 & 87.6 & 91.9 & 91.1 \\
\hline C-3' & 87.9 & 88.3 & 87.5 & 87.1 \\
\hline C-4' & 70.0 & 70.2 & 70.4 & 69.9 \\
\hline C-5' & 83.7 & 83.8 & 83.6 & 83.4 \\
\hline C-6' & 60.6 & 60.9 & 61.2 & 60.8 \\
\hline C-2 & 153.0 & 154.1 & 154.5 & 149.5 \\
\hline C-4 & 149.1 & 150.9 & 166.3 & 164.2 \\
\hline C-5 & 118.7 & 116.7 & 94.8 & 110.1 \\
\hline C-6 & 156.2 & 157.1 & 142.5 & 137.2 \\
\hline C-8 & 138.7 & 134.9 & - & - \\
\hline $\mathrm{CH}_{3}(\mathrm{~T})$ & - & - & - & 11.9 \\
\hline
\end{tabular}

*The ${ }^{13} \mathrm{C}-\mathrm{NMR}$ data for the oxetane- $\underline{\mathbf{C}}(\mathbf{1} \mathbf{a})$ in $\mathrm{D}_{2} \mathrm{O}$ and the oxetane- $\underline{\mathbf{T}}(\mathbf{1 b})$ in methanol- $d_{4}$ have been reported in ref. 24 and $22 \mathrm{~b}$ respectively. 


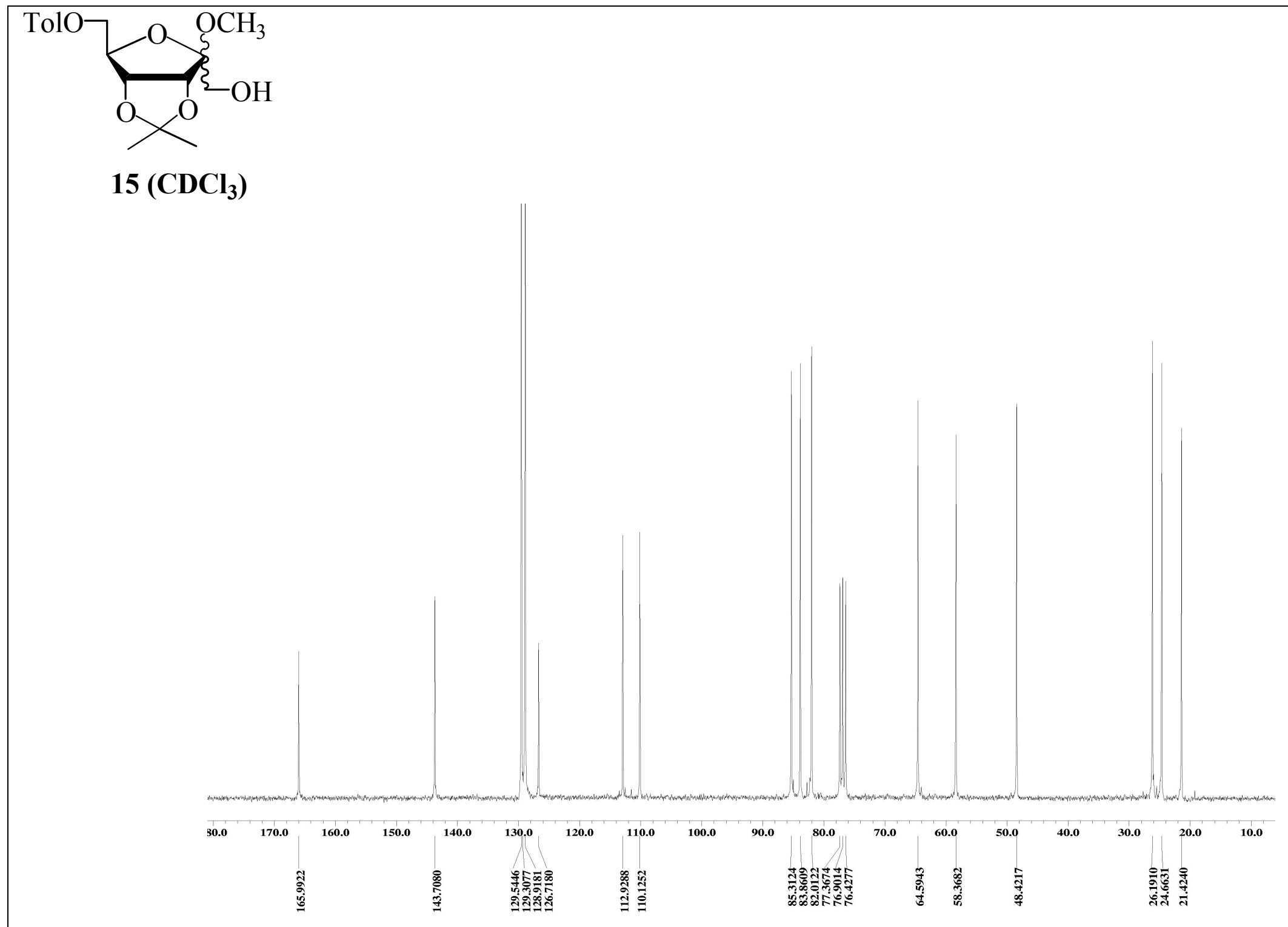

Figure S5 


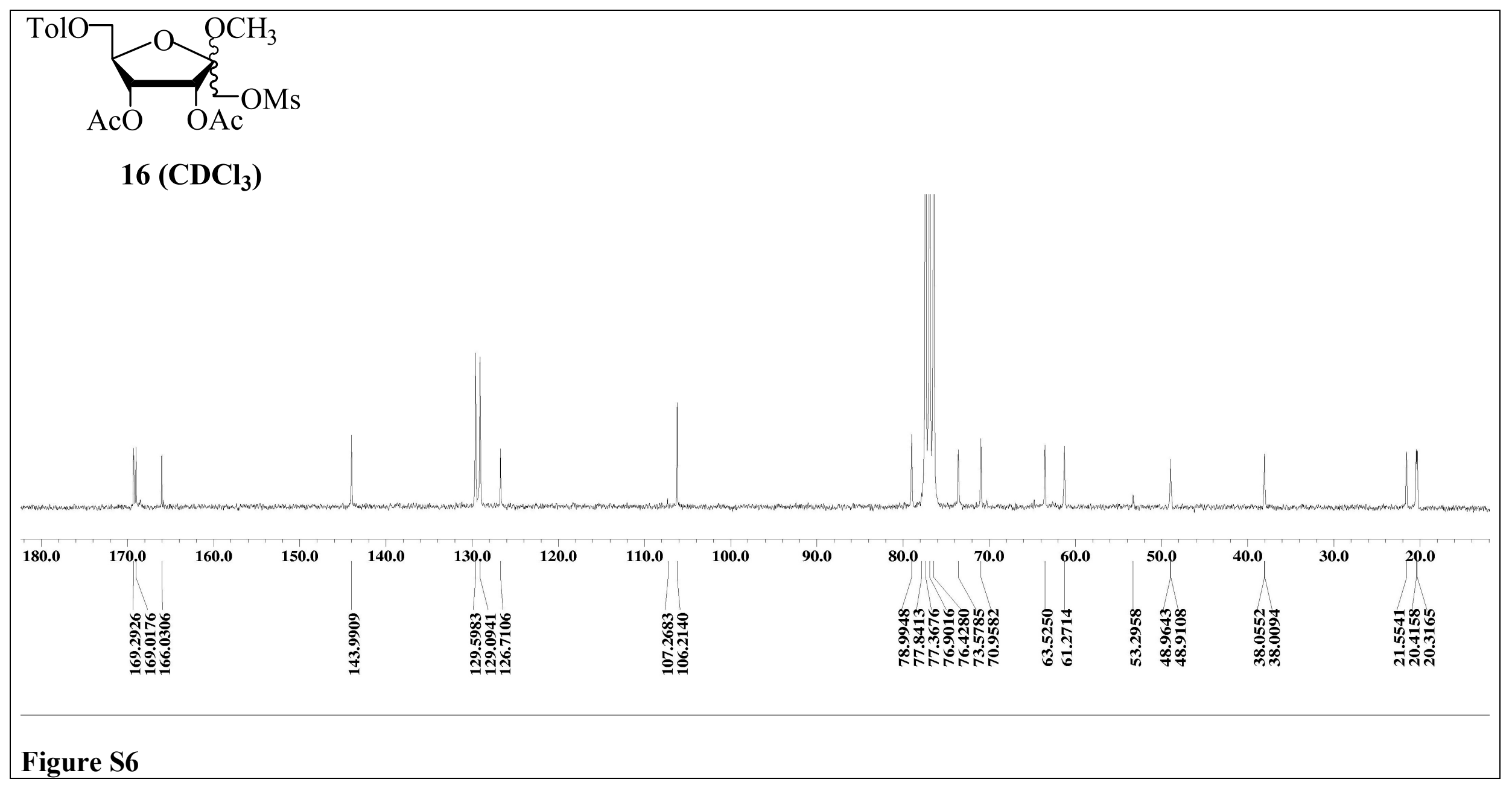




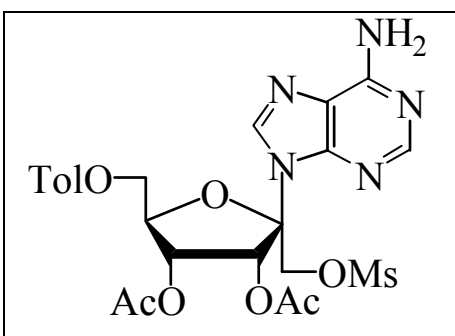

$18 \mathrm{a}\left(\mathrm{CDCl}_{3}\right)$

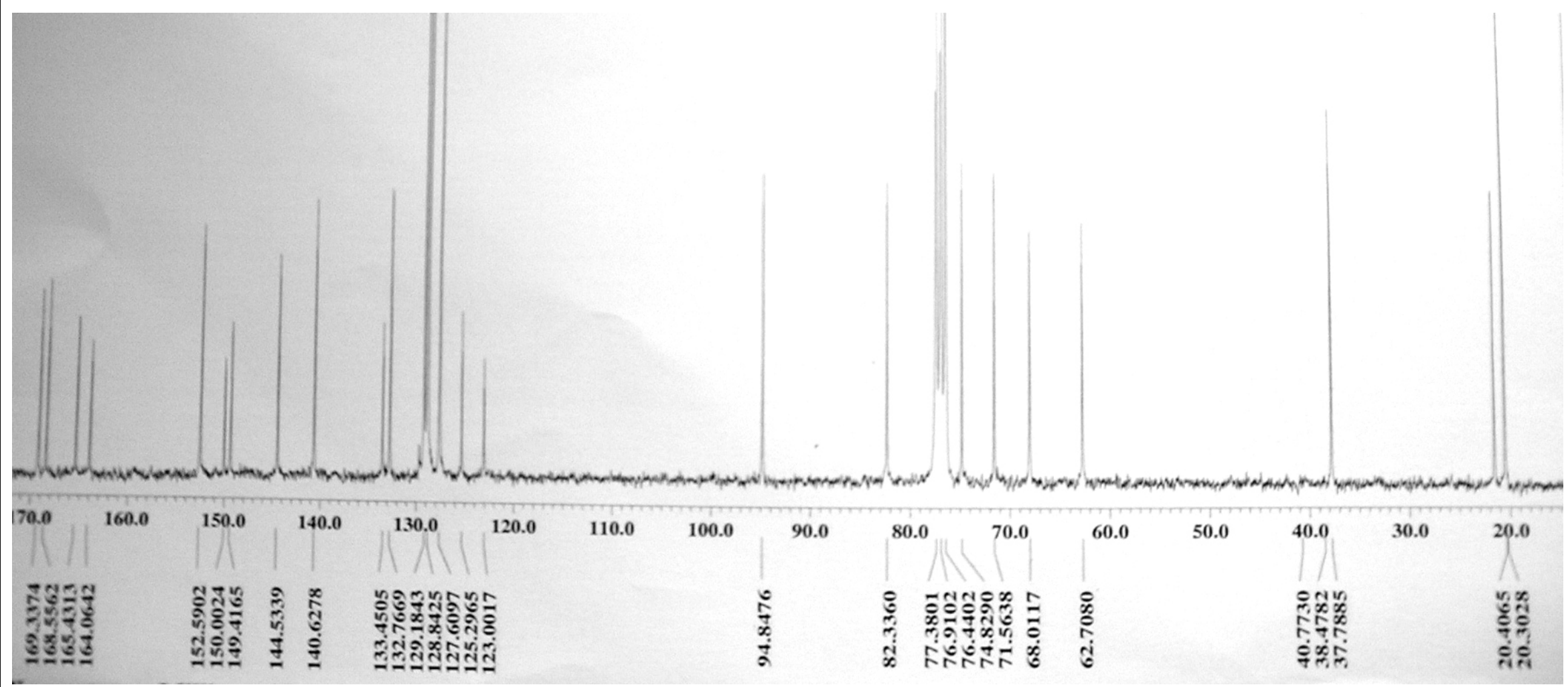

Figure S7 


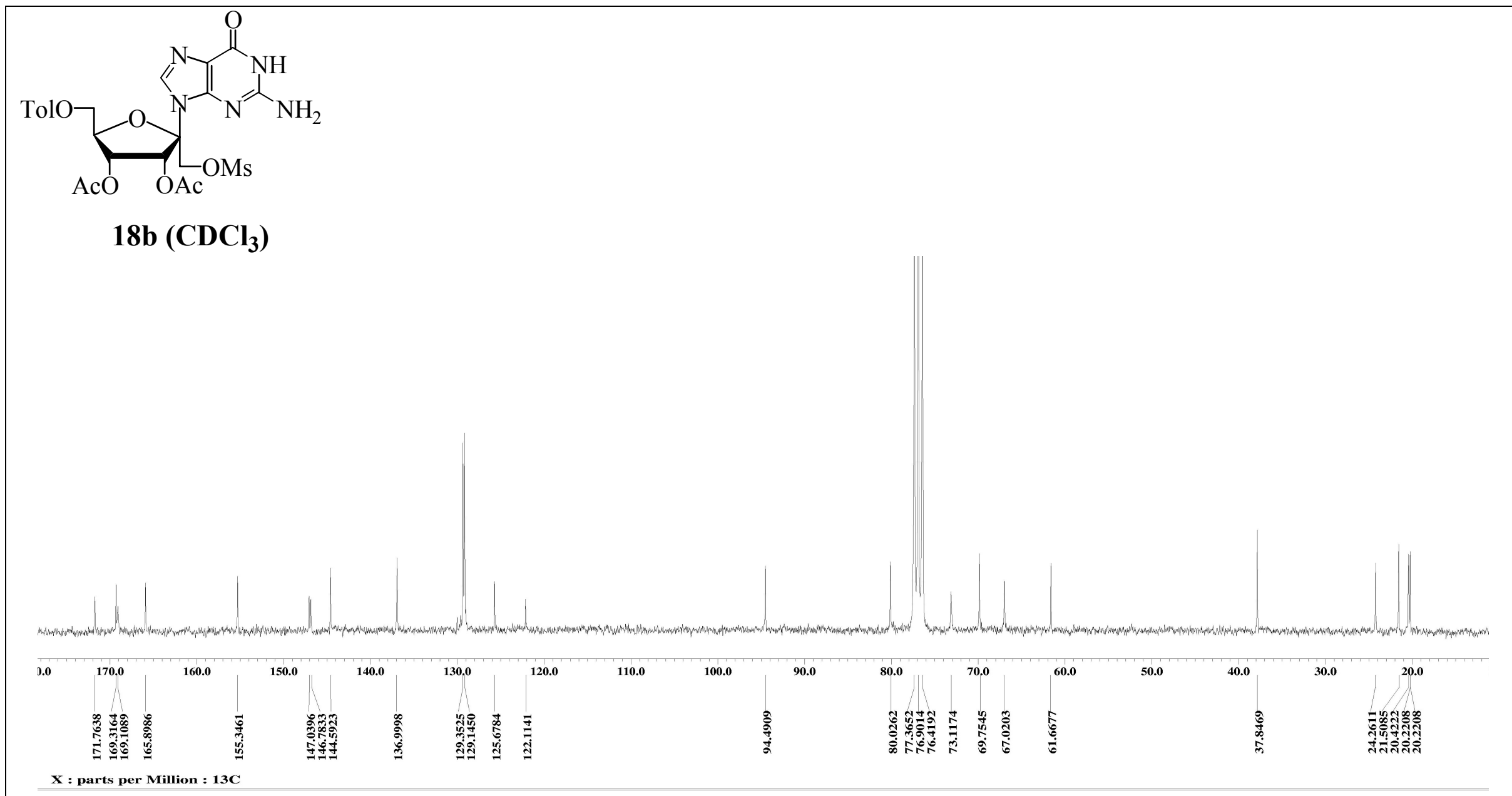

Figure S8 


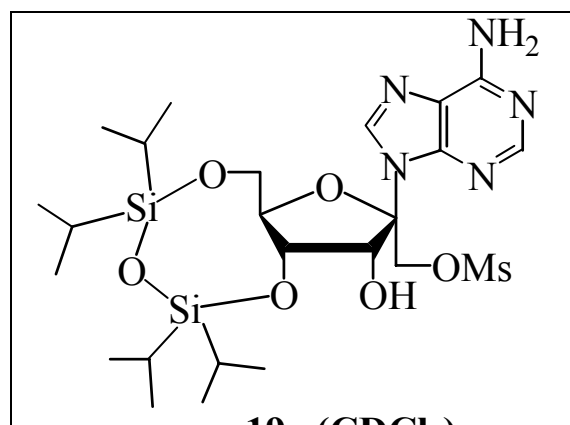

19a $\left(\mathrm{CDCl}_{3}\right)$

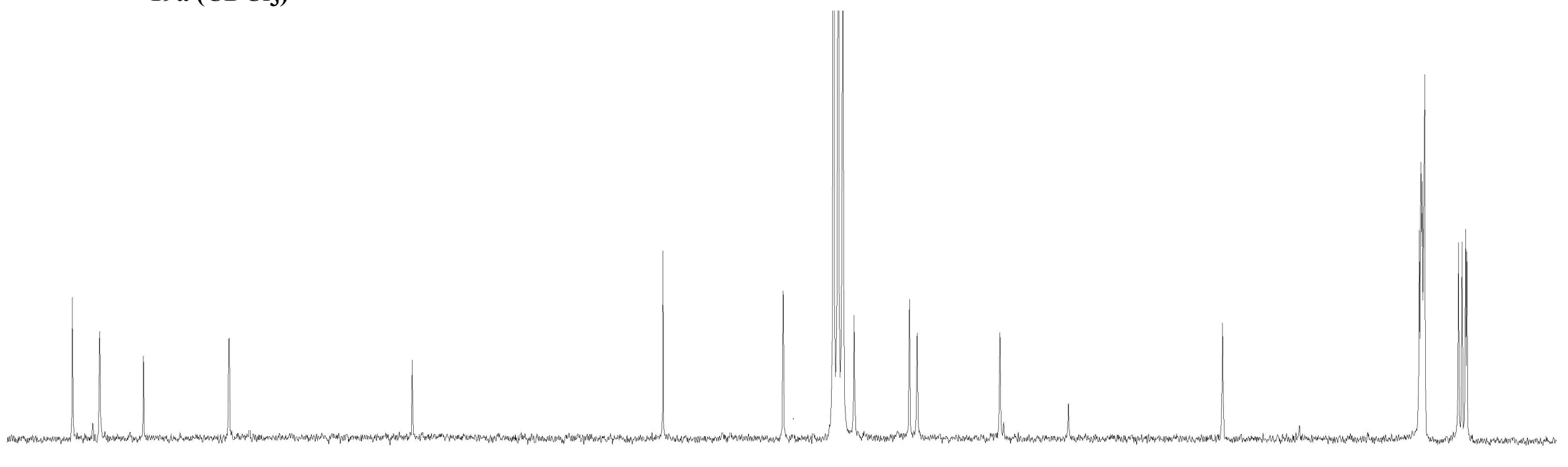

160.

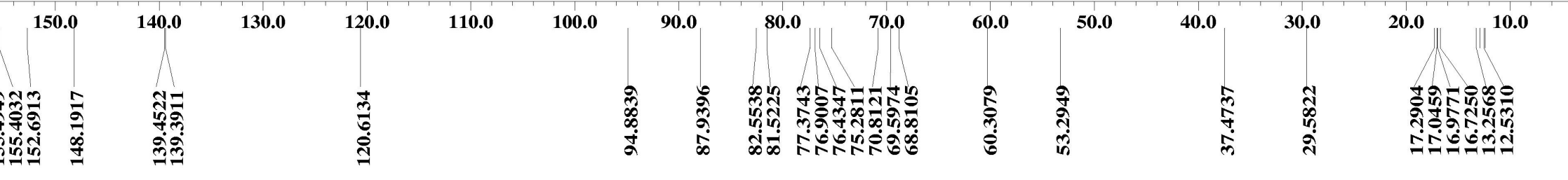

Figure S9 


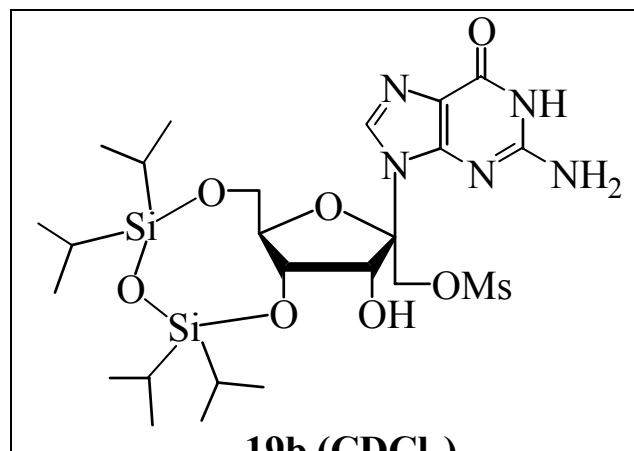

$19 \mathrm{~b}\left(\mathrm{CDCl}_{3}\right)$

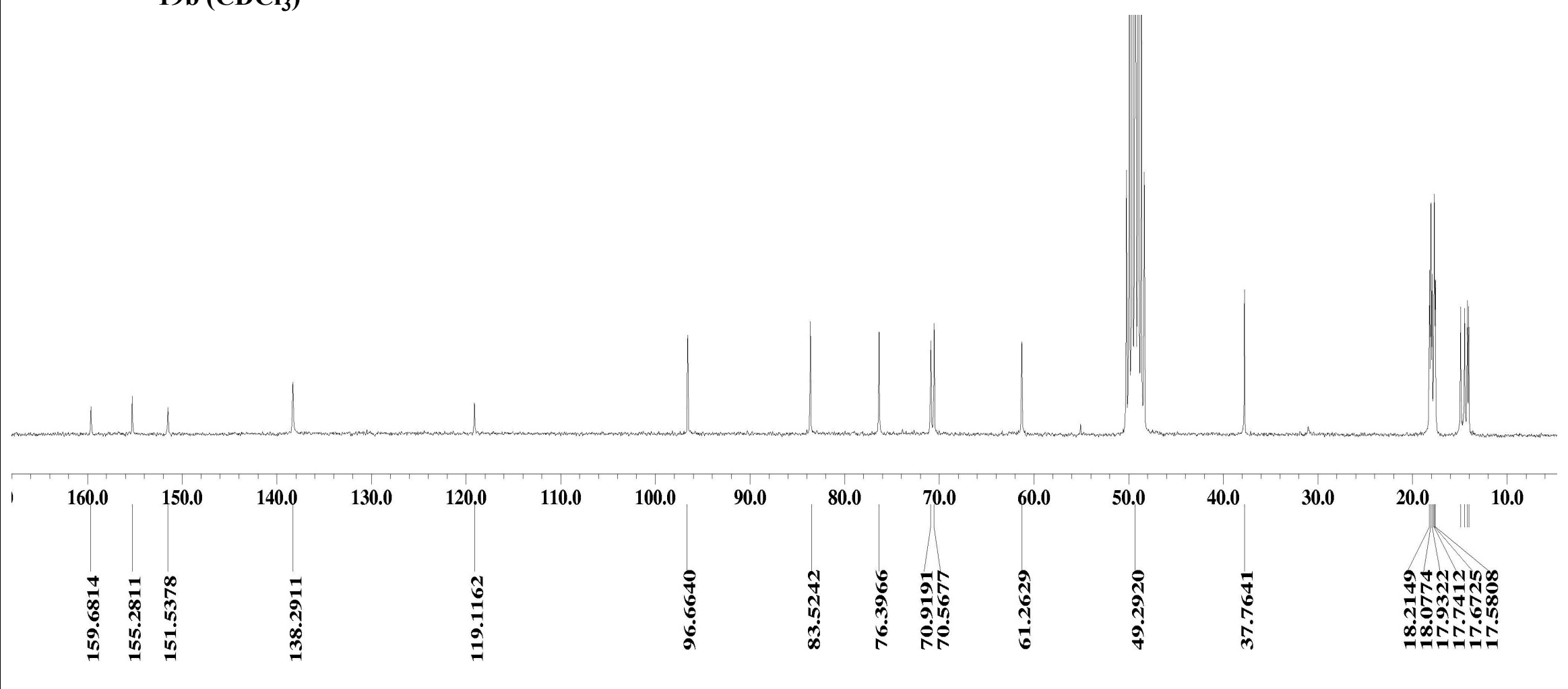

Figure S10 


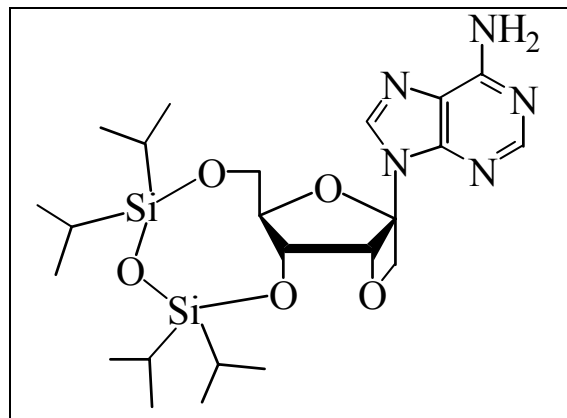

20a $\left(\mathrm{CDCl}_{3}\right)$

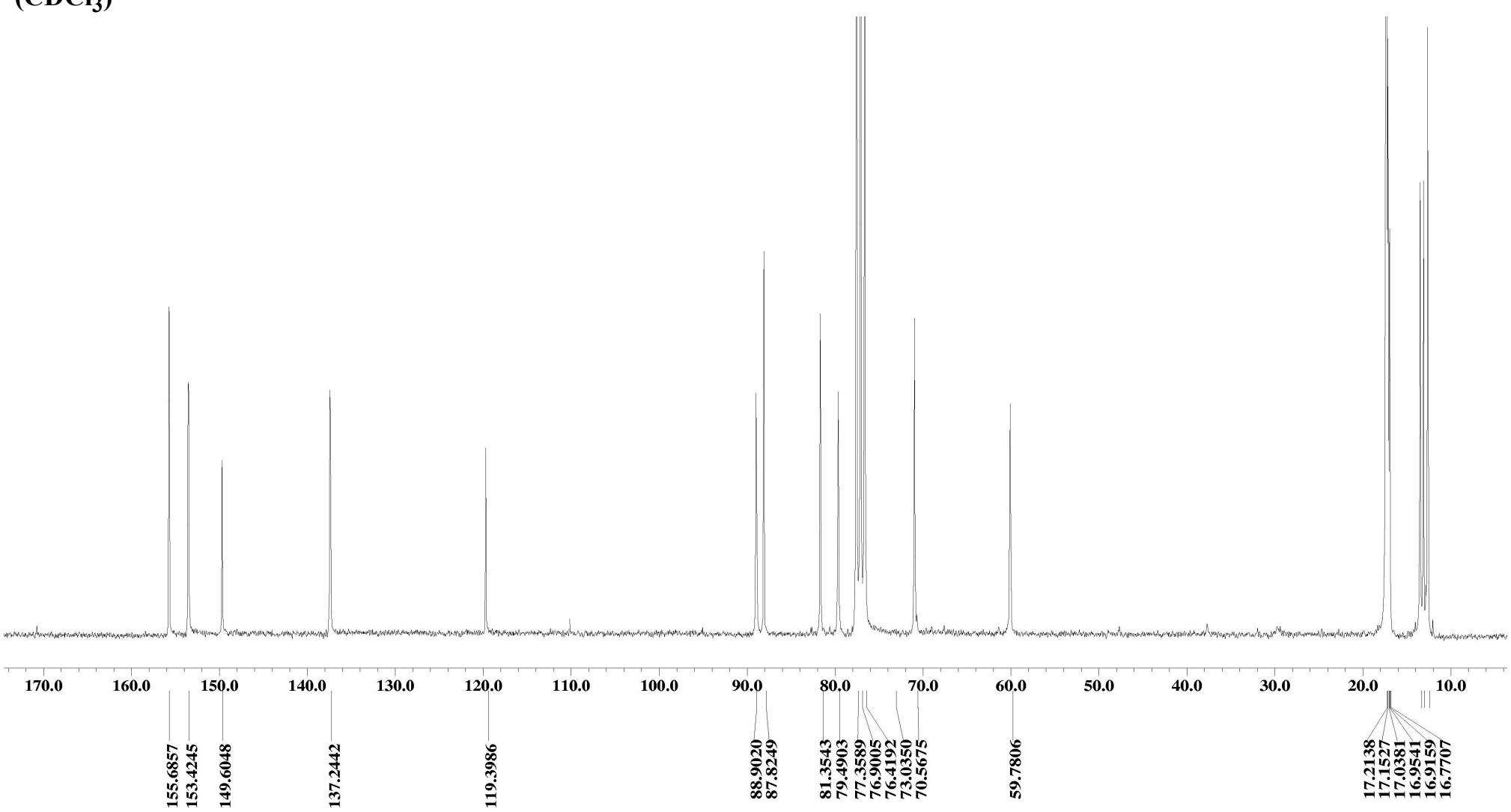

Figure S11 


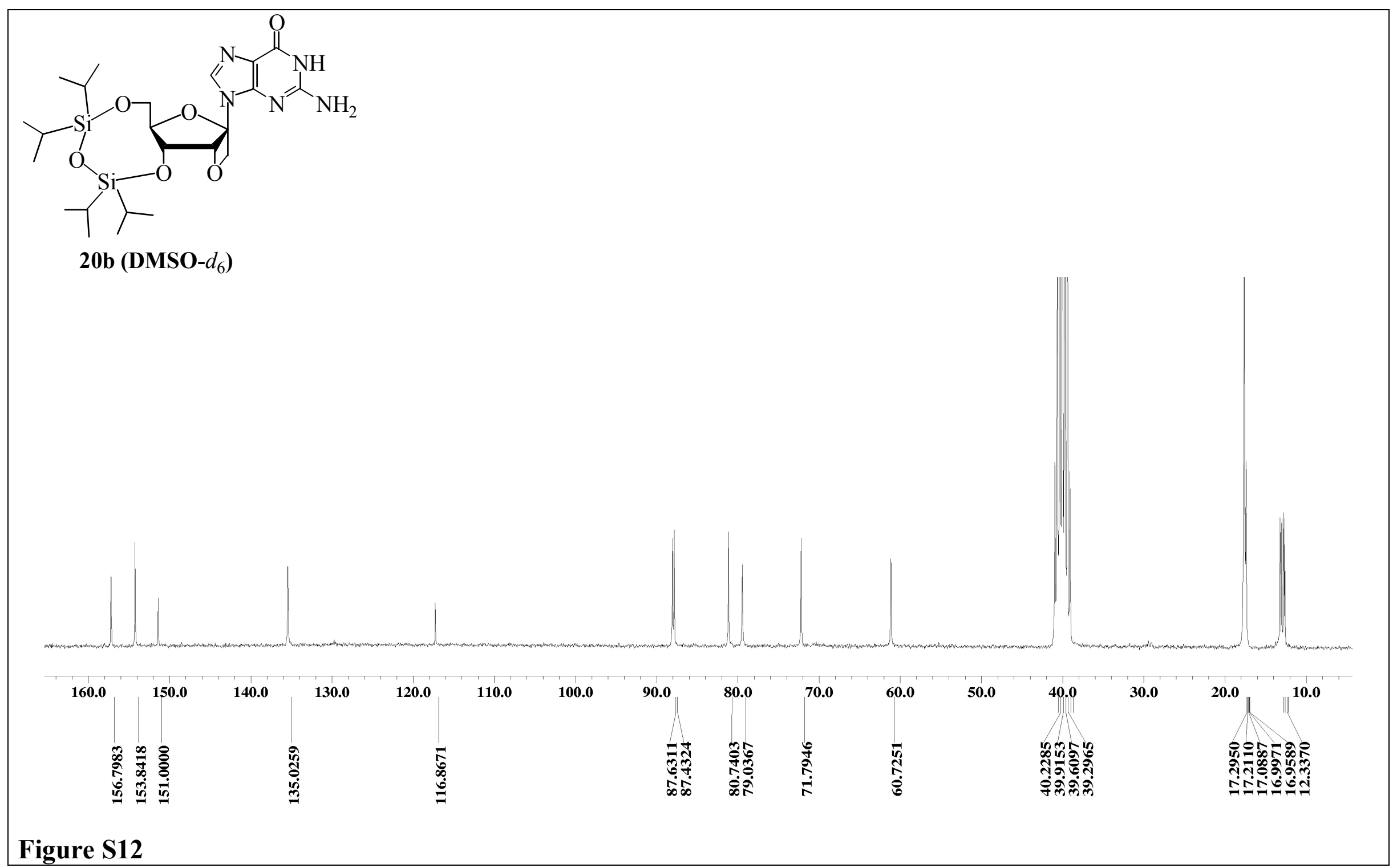




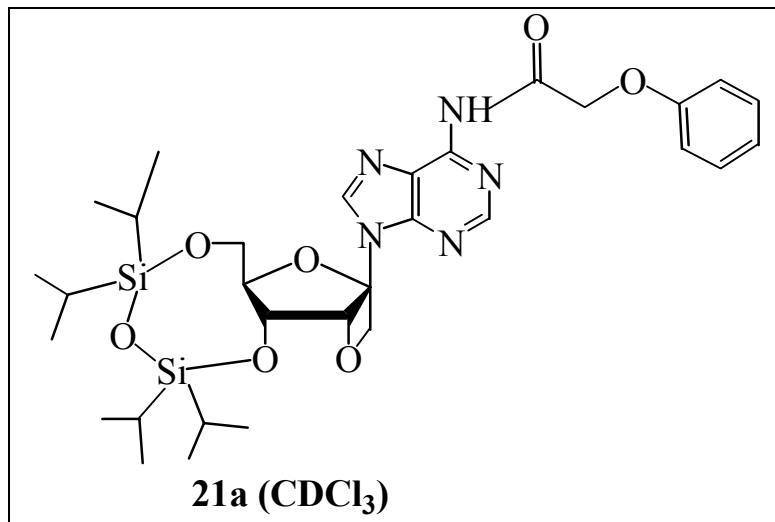

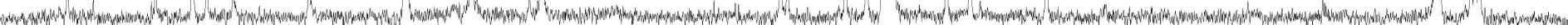

\begin{tabular}{|c|c|c|c|c|c|c|c|c|c|c|c|c|c|c|c|}
\hline 170.0 & 160.0 & 150.0 & 140.0 & 130.0 & 120.0 & 110.0 & 100.0 & 90.0 & 80.0 & 70.0 & 60.0 & 50.0 & 40.0 & 30.0 & \\
\hline 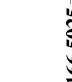 & & 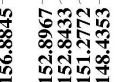 & 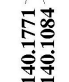 & \begin{tabular}{l}
$E$ \\
\multirow{2}{*}{}
\end{tabular} & 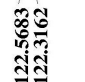 & & & 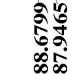 & 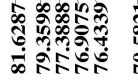 & 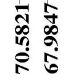 & 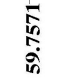 & & & & 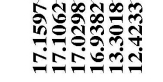 \\
\hline
\end{tabular}

Figure S13 

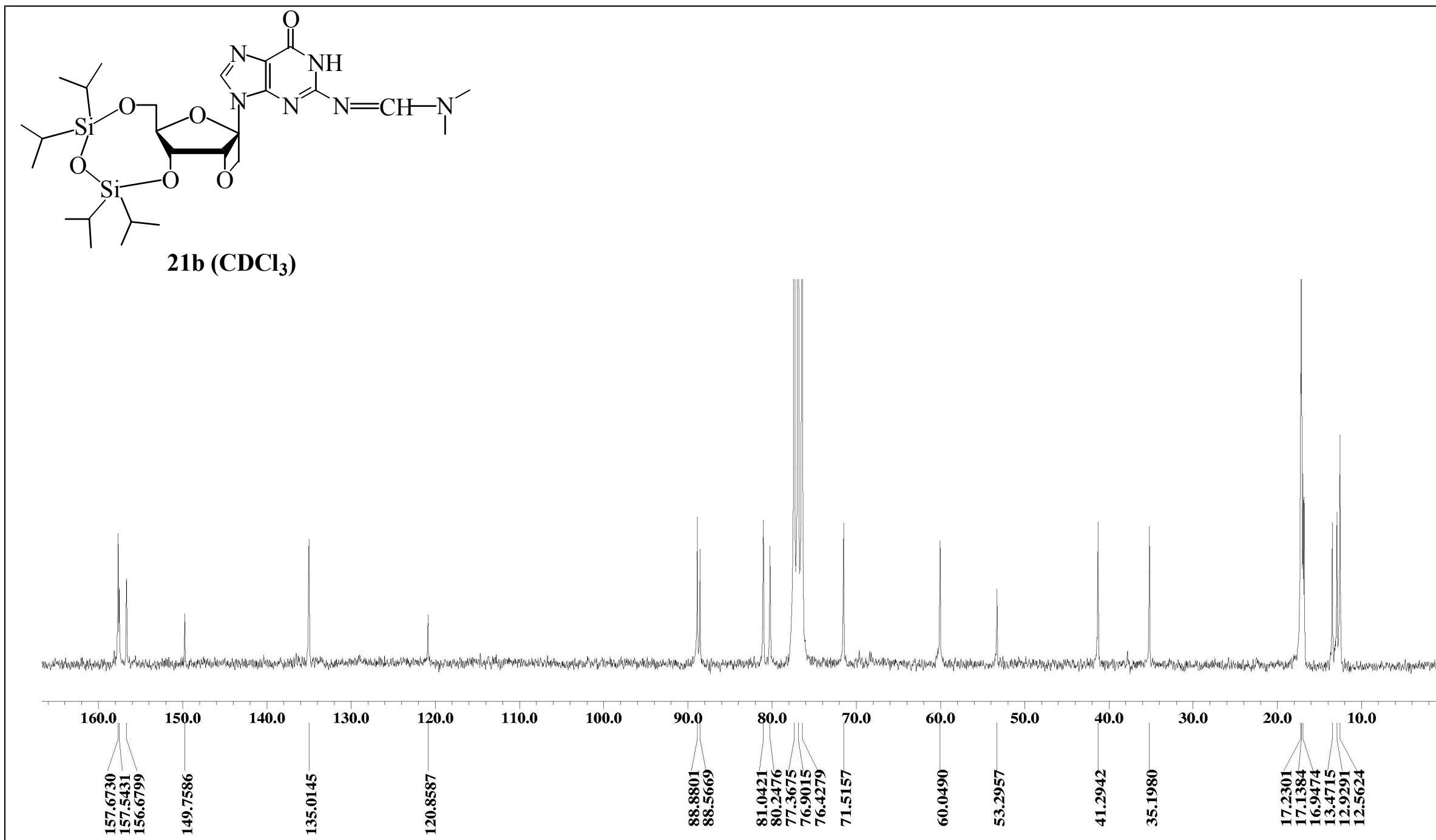

Figure S14 


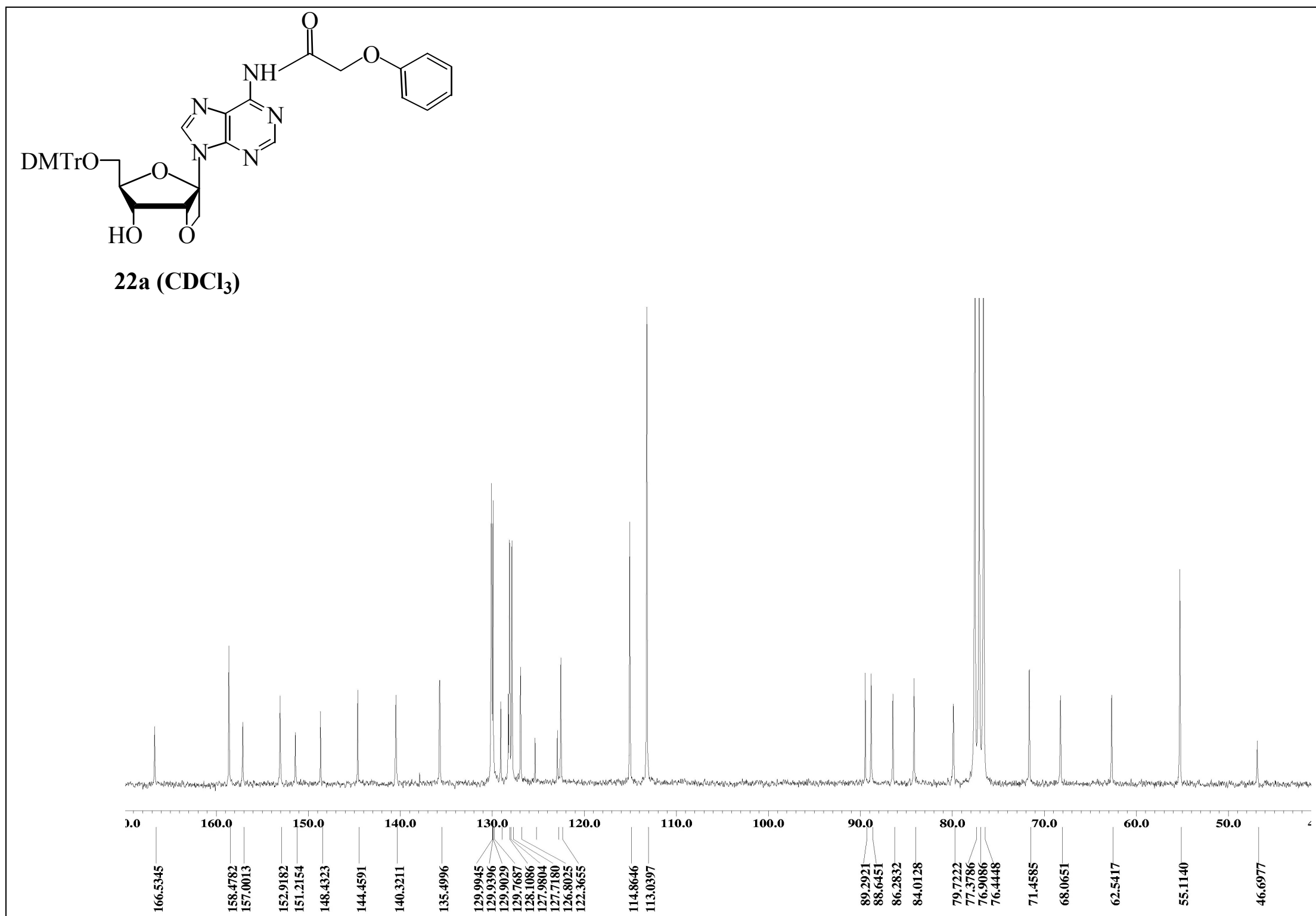

Figure S15 


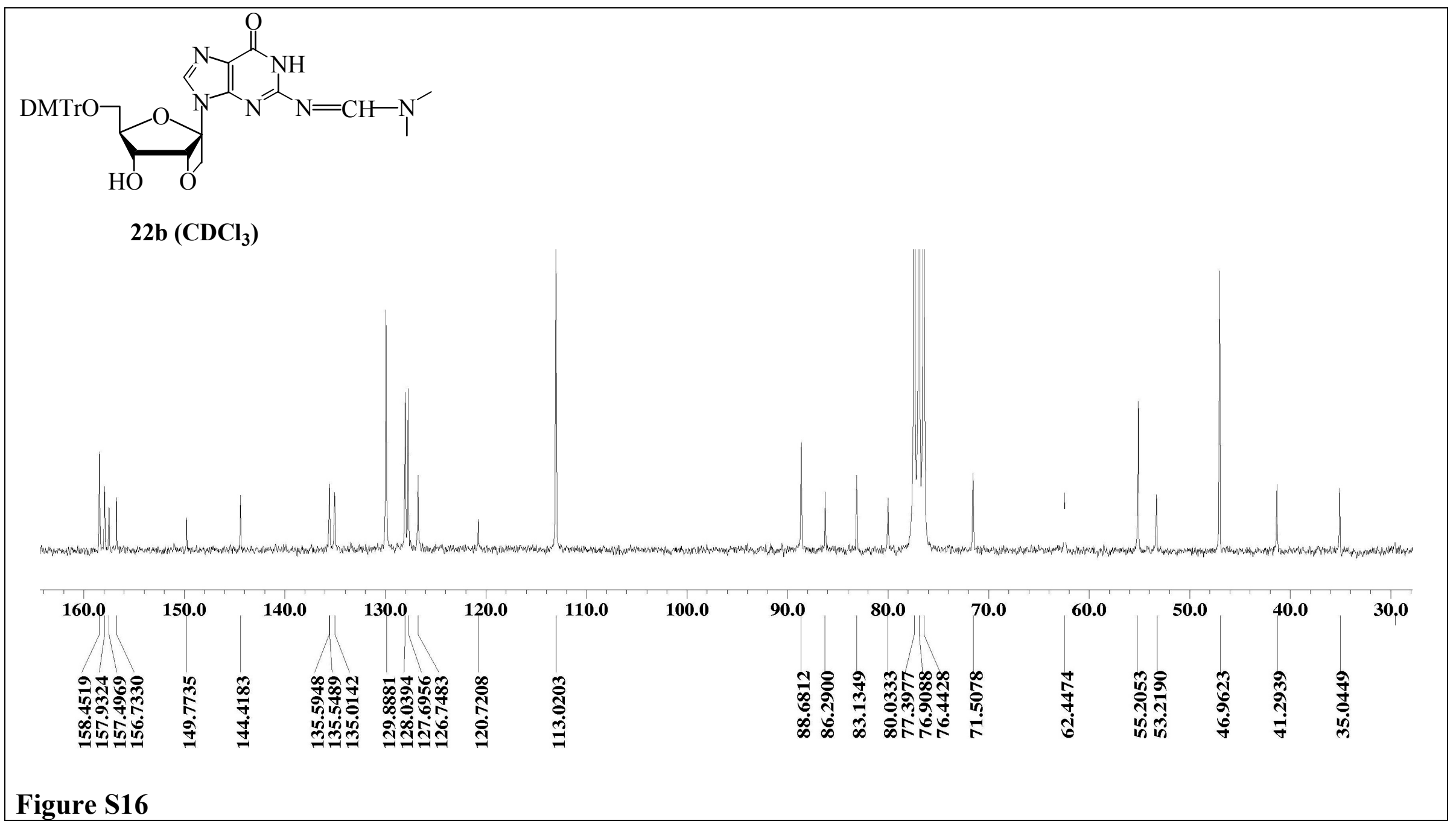




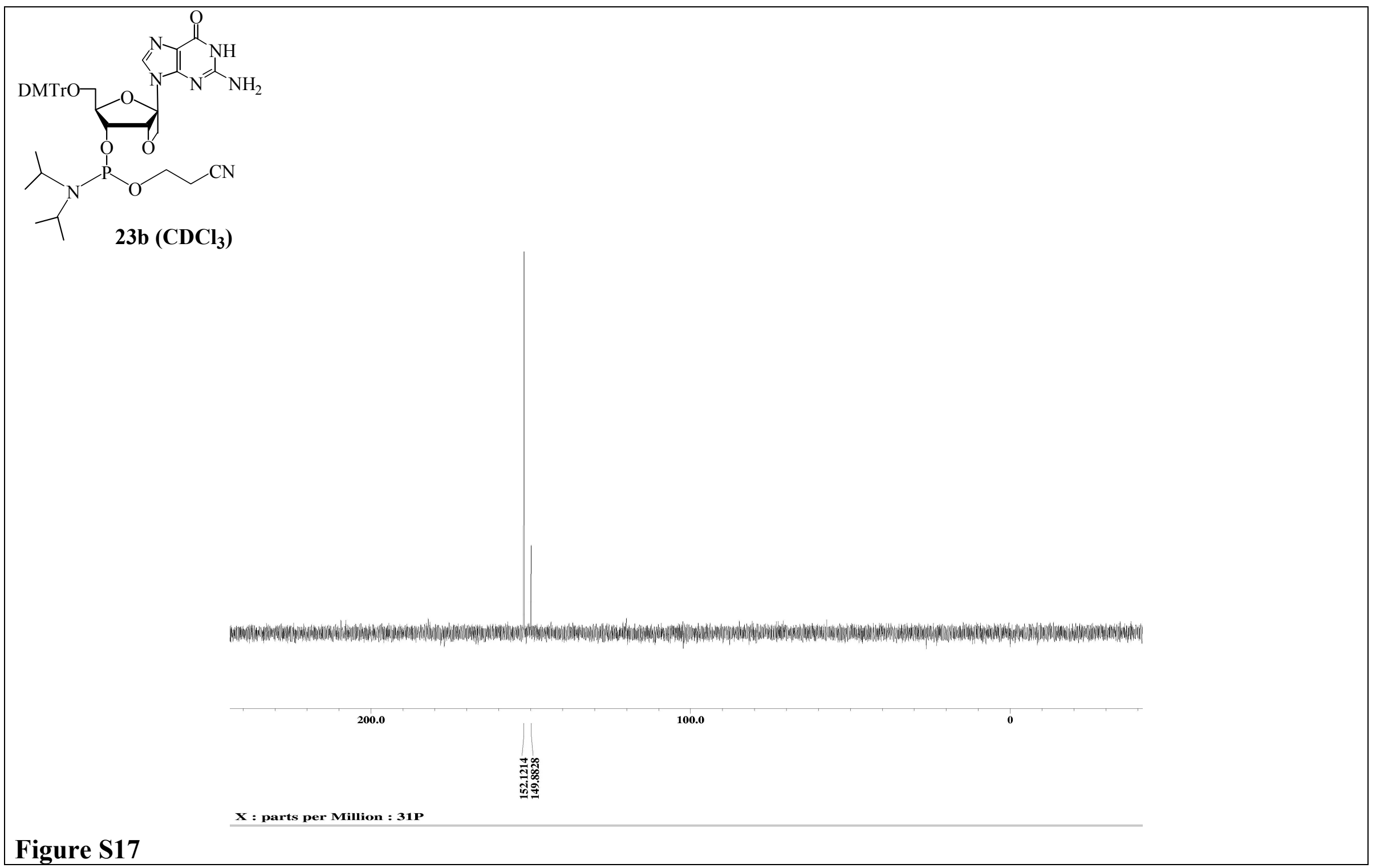




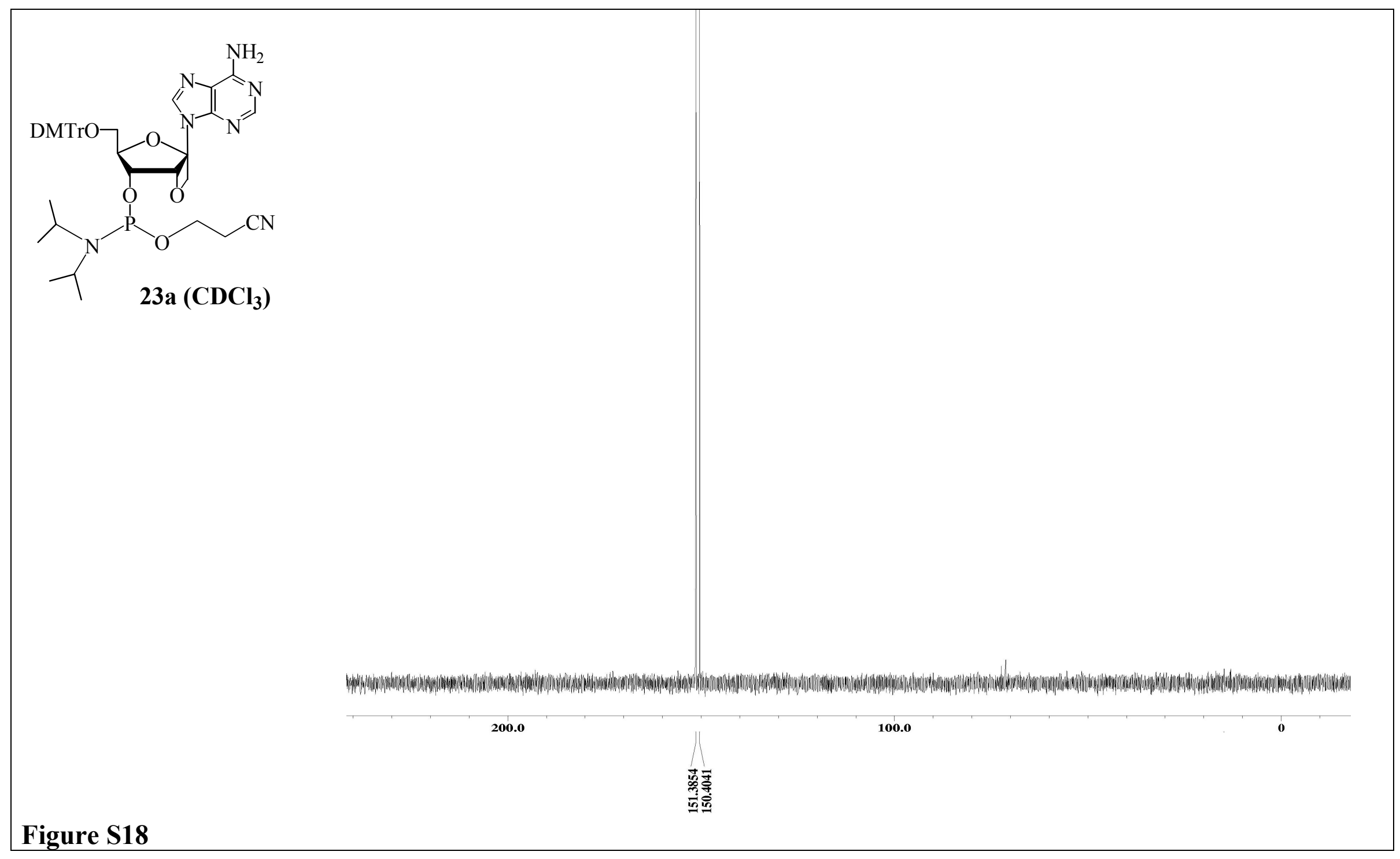




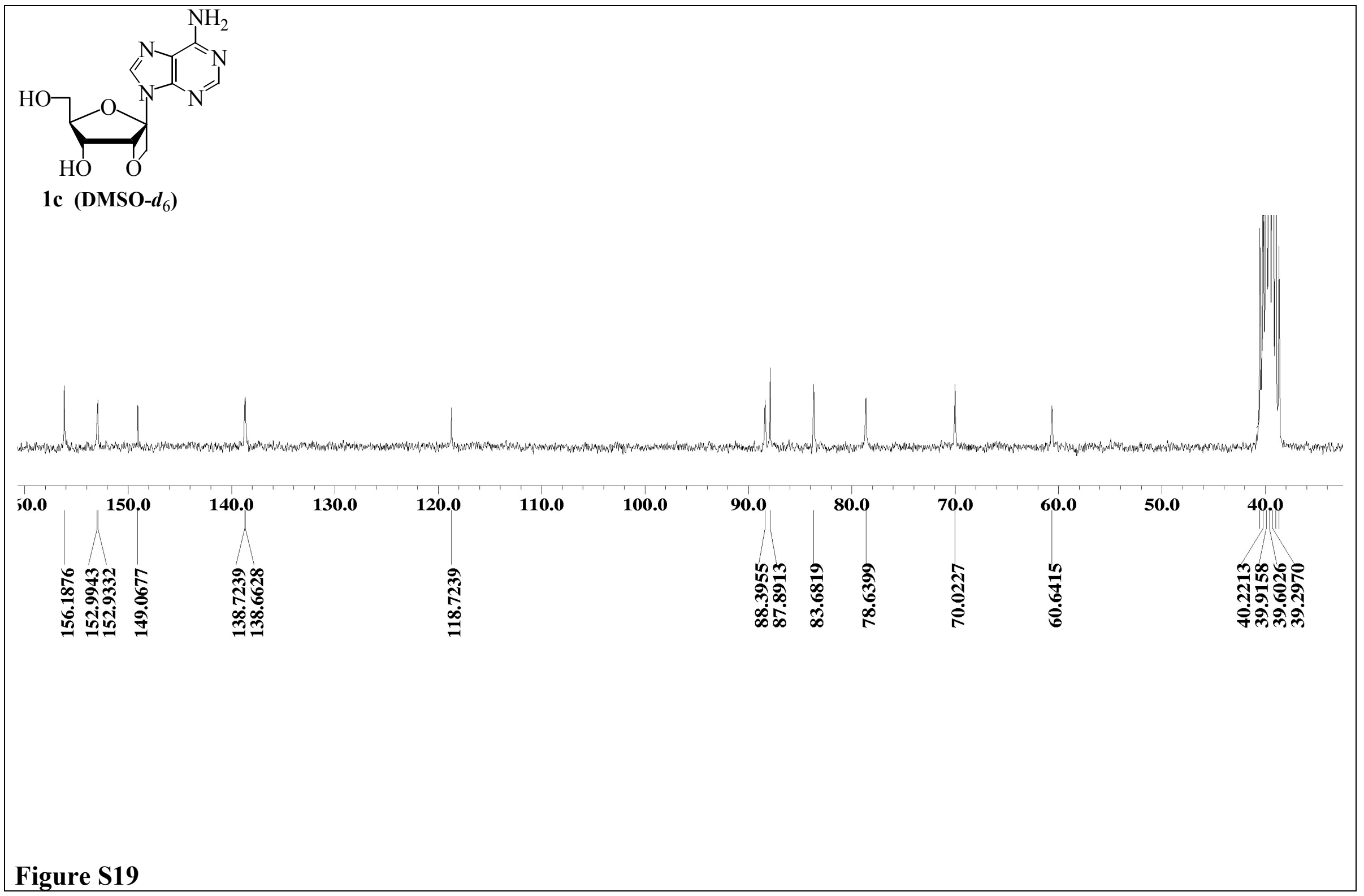




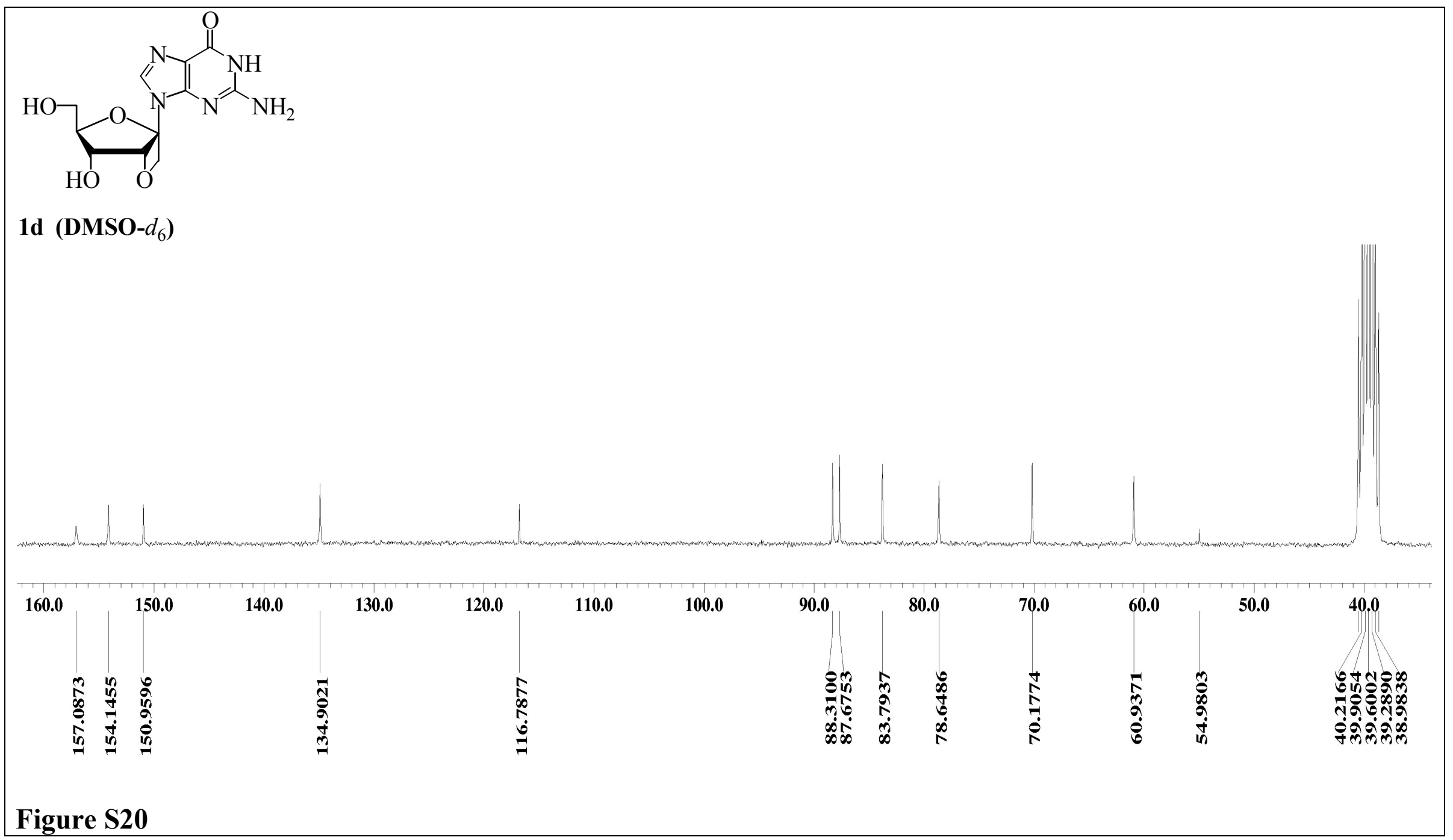

